\title{
Age, frequency, and iconicity in early sign language acquisition: Evidence from the Israeli Sign Language MacArthur-Bates Communicative Developmental Inventory
}

\author{
Rama Novogrodsky ${ }^{1, *(D)}$ and Natalia Meir $^{2}$ (D) \\ ${ }^{1}$ University of Haifa and ${ }^{2}$ Bar-Ilan University \\ *Corresponding author. Email: rnovogr1@univ.haifa.ac.il
}

(Received 27 April 2019; revised 29 April 2020; accepted 15 May 2020; first published online 24 July 2020)

\begin{abstract}
The current study described the development of the MacArthur-Bates Communicative Developmental Inventory (CDI) for Israeli Sign Language (ISL) and investigated the effects of age, sign iconicity, and sign frequency on lexical acquisition of bimodal-bilingual toddlers acquiring ISL. Previous findings bring inconclusive evidence on the role of sign iconicity (the relationship between form and meaning) and sign frequency (how often a word/sign is used in the language) on the acquisition of signs. The ISL-CDI consisted of 563 video clips. Iconicity ratings from 41 sign-naïve Hebrew-speaking adults (Study 1A) and sign frequency ratings from 19 native ISL adult signers (Study 1B) were collected. ISL vocabulary was evaluated in 34 toddlers, native signers (Study 2). Results indicated significant effects of age, strong correlations between parental ISL ratings and ISL size even when age was controlled for, and strong correlations between naturalistic data and ISL-CDI scores, supporting the validity of the ISL-CDI. Moreover, the results revealed effects of iconicity, frequency, and interactions between age and the iconicity and frequency factors, suggesting that both iconicity and frequency are modulated by age. The findings contribute to the field of sign language acquisition and to our understanding of potential factors affecting human language acquisition beyond language modality.
\end{abstract}

Keywords: Sign language; vocabulary; acquisition; iconicity; frequency

\section{Introduction}

Vocabulary size is a sensitive measure of language acquisition in toddlers. Vocabulary tests are valid assessment tools that predict later language development in spoken (e.g., Bavin et al., 2013; Rowe et al., 2012) and sign languages (Lee, 2011). Vocabulary growth rate is an important measure of language development in children with hearing impairments (Lederberg \& Spencer, 2001; Nicholas \& Geers, 2006; Tomblin et al., 2005). It enables professionals to identify language

(C) Cambridge University Press 2020. This is an Open Access article, distributed under the terms of the Creative Commons Attribution licence (http://creativecommons.org/licenses/by/4.0/), which permits unrestricted re-use, distribution, and reproduction in any medium, provided the original work is properly cited. 
delays and language deprivation ${ }^{1}$ among young children (e.g., Arriaga et al., 1998; Fenson et al., 2000b; Mancilla-Martinez et al., 2011) and children with atypical language acquisition (e.g., Mitchell et al., 2006). Different lexical characteristics tend to affect early vocabulary acquisition, for example, part of speech, concreteness, babiness (the word's relevance to babies), and frequency (Braginsky et al., 2016). Furthermore, different languages show unique acquisition trajectories and specific characteristics (see, e.g. Perlman et al., 2018, for a comparison of four languages: two spoken and two sign languages for the effect of iconicity) supporting the importance of cross-linguistic research (Bornstein et al., 2004).

One established measure of vocabulary size is the MacArthur Communicative Development Inventory (CDI) (Fenson et al., 1994). The CDI is a checklist in which parents, caregivers, or teachers indicate whether a child can comprehend and/or produce words/signs reflecting early language acquisition. It was developed originally for American English and was adapted to more than 60 spoken languages (Frank et al., 2017) including Hebrew (Maital et al., 2000) and several sign languages (e.g., Anderson \& Reilly, 2002; Rodríguez-Ortiz et al., 2020; Sümer et al., 2017; Woolfe et al., 2010). The checklist includes hundreds of words representing different categories, such as predicates, nouns, and function words (Braginsky et al., 2016; Frank et al., 2017).

The current study was twofold. First, its aim was to develop a MacArthur-Bates Communicative Development Inventory (CDI) (Fenson et al., 1994) for Israeli Sign Language (ISL) (hereinafter ISL-CDI). Second, on the theoretical side, the study was devised to evaluate the effects of age, sign iconicity, and sign frequency on lexical acquisition in ISL in bimodal-bilingual children who acquire ISL from birth. Previous research brings conflicting evidence on the effects of frequency and iconicity in sign language acquisition.

\section{Israeli sign language}

ISL is the major sign language of the Israeli deaf community. It emerged in the 1930s and 1940s with the formation of the deaf community in Israel and the language is now in its fourth generation. Many immigrants from all around the world brought with them sign languages and home sign systems from their countries of origin. These languages influenced the lexicon of ISL. Today, ISL is widely used by about 10,000 signers and, like any language, it is used across all aspects of life (Sandler, 2018). Linguistic characteristics of ISL are documented in numerous publications (e.g., Dachkovsky \& Sandler, 2009; I. Meir, 2002, 2003, 2006). As in the case of other sign languages, the lexicon of ISL is independent from the societal spoken language, Hebrew, and, in many instances, it reflects semantic distinctions that do not appear in the societal spoken language. For example, the Hebrew word "ahava" meaning love has two ISL signs, one sign denotes love for inanimate objects and the other sign denotes love for animate beings. We adapted the ISL-CDI from the HebrewCDI (Gendler-Shalev \& Dromi, 2020) based on the assumption that the experience and cultural background of Hebrew toddlers would be the closest to the toddlers using ISL. Similarly, previous studies developing adaptations for a national sign 
language were based on the dominant spoken language. For example, the CDI adaptation for Spanish Sign Language was developed based on Spanish (Rodríguez-Ortiz et al., 2020). Signers of ISL are integrated within the society of Hebrew speakers and many of them are bimodal-bilingual. Support for the similarities between the vocabularies of the spoken and sign languages can be found in Anderson and Reilly (2002) for American Sign Language of deaf signers and in Rinaldi et al. (2014) for Italian Sign Language of deaf signers. In both studies, the vocabulary of the CDI version for sign languages was comparable to that of the spoken language of children speaking the society language: English and Italian.

The adaptation in the current study took into consideration modality and language-specific properties of Hebrew and ISL, and these are described in the "Methods" subsection. For example, we excluded some signs for body parts that are represented by pointing. ${ }^{2}$ Furthermore, the nonsign gestures section was excluded from the CDI to focus exclusively on the lexicon and reduce confusion between signs and gestures by the parents who fill in the questionnaire (for a detailed review on adapting sign language tests from a spoken language see Haug, 2011).

\section{Sign language acquisition}

Direct measures of vocabulary assessment and parental questionnaires tapping into vocabulary development in sign languages show positive correlations between chronological age and vocabulary size (e.g., for British Sign Language [Thompson et al., 2013]; for American Sign Language [Caselli \& Pyers, 2017]; and for Turkish Sign Language [Sümer et al., 2017]). As children grow older, they score higher on vocabulary size measures, similarly to children who acquire spoken languages (Frank et al., 2017). Following these studies, our study also aimed to investigate whether vocabulary size in ISL of bimodal-bilingual children is associated with age (Study 2), which was also used to support the validation of the ISL-CDI.

Deaf children of deaf parents acquire two languages, some of them become bilingual during school age; others become bimodal-bilingual. Bilingual children use sign language as their home language and acquire the written modality of the spoken language later during school years. Yet, today with the advancement in technology many of the deaf children of deaf parents are bimodal-bilingual at preschool age. By means of hearing aids and cochlear implants, deaf children born to deaf parents have access to auditory input that allows them to acquire the spoken language at younger ages in its spoken modality. In previous studies, native signing toddlers are defined as monolinguals because they were exposed only to a sign language (e.g., Woolfe et al., 2010). The children in the current study were early bimodal-bilinguals. They were exposed to both ISL and Hebrew and had partial auditory capacity to perceive the spoken language in addition to their native ISL (as described in more details in the "Methods" subsection of Study 2).

It is well-documented in the literature that language skills of bilingual children who are exposed to two spoken languages are often unevenly distributed across and within the languages spoken by the child (Kohnert, 2010). In the same vein, bimodal-bilingual children's language proficiency and language dominance can 
vary across the two modalities: the sign and the spoken. Vocabulary size of bimodalbilingual children should be assessed in both languages, similarly to bilingual children who acquire two spoken languages (e.g., Armon-Lotem et al., 2015). Yet, currently, there are no available tools to assess children's language skills in ISL, while in Hebrew there is a range of standardized assessment measures (e.g., the Hebrew-CDI [Gendler-Shalev \& Dromi, 2020]; Goralnik screening test for Hebrew [Goralnik, 1995]). Thus, the current study aimed to address this gap by developing ISL-CDI.

There is a scarcity of research on vocabulary acquisition of bimodal-bilingual children. These existing studies support the importance of testing both languages of bimodal-bilingual due to the specific trajectories of each language. For example, Rinaldi et al. (2014) showed that acquisition trajectories of lexical categories differ between sign and spoken languages. Using a naming-picture naming, the authors showed that 2-3-year-old signers scored higher on signs that describe actions (predicates/verbs) compared to signs that describe objects (nominal/nouns) (Rinaldi et al., 2014). The toddlers acquiring spoken language showed an opposite pattern: they scored higher on nouns compared to verbs. Another reason to test both languages of bimodal-bilinguals is their smaller vocabulary size shown when being tested in only one language compared to hearing peers. The smaller vocabulary size of signing toddlers compared to hearing children (Rinaldi et al., 2014; Woll, 2013) can be explained by their bilingual status (Rinaldi et al., 2014). Previous studies demonstrated that bilingual children who acquire two spoken languages might have smaller vocabularies in one of their languages when compared to their monolingual peers, especially in the societal language (for an overview see Gatt et al., 2015). Thus, it is highly important to assess the vocabulary size in the sign language of bimodal-bilingual toddlers.

\section{Iconicity of signs and sign language acquisition}

Word learning requires mapping information about its form onto its meaning. Iconicity is a relationship of similarity between the two aspects of a word or a sign: its form and its meaning. An iconic sign/word is one whose form represents its meaning in some way (Dingemanse et al., 2015; I. Meir \& Tkachman, 2018). Iconicity has different features (Winter et al., 2017), for example, in spoken languages it can be the sound of the form (e.g., onomatopoeic words like buzz in English, representing the sound of the concept) or the repetition of the form (e.g., ideophonic words like "kibikibi" ["energetic" in Japanese], which includes repeated forms representing repeated events) (for an overview of iconicity in language, see Dingemanse et al., 2015). In sign languages it is the visual structure of the form (e.g., the sign TO EAT in ISL mimics the action of eating) (following convention, all English glosses of ISL signs are written in capital letters). This means that iconicity represents the visual similarity between the sign form and its meaning.

Iconicity in sign languages is usually present in one or more of the phonological parameters of the sign: the shape of the hands, the location of the hands in space or on the body, and/or the movement of the hand (Perniss et al., 2010). Iconic mapping goes beyond a simple relationship of form to meaning, and different factors affect it, such as age, linguistic experience, and cultural background (Ortega, 2017). This 
mapping is commonly present across languages, specifically in sign languages (Dingemanse et al., 2015; Perniss et al., 2010). However, not all signs are iconic, in line with the agreed assumption that in many cases there is an arbitrary link between form and meaning (de Saussure, 1916).

In acquisition of spoken languages, iconic words, are common in children's early words (Laing et al., 2017; Perry et al., 2018). For example, Massaro and Perlman (2017) showed that words learned earlier tended to be more iconic, suggesting that iconicity in early vocabulary may facilitate word learning. With increases in vocabulary size, the effect of iconicity diminishes dramatically. Yet, it should be noted that the effect of iconicity is independent from the influence of concreteness, difficulty of articulation, and parental input frequency. Another more specific iconicity effect is reported in the study by Maurer et al.'s study (2006). The authors found that 2.5-year-olds were sensitive to the structure of vowels in words: similarly to adults' performance, children consistently matched words with rounded vowels (e.g., "bouba") to round shapes and words with unrounded vowels (e.g., "kiki") to pointed shapes. These findings provide evidence that iconicity is an important property of spoken languages.

Early work on sign languages showed contradictory findings. For example, Orlansky and Bonvillian (1984) found that only one third of early-acquired signs is iconic, reflecting the overall proportion of iconic signs in American Sign Language. Yet, recent studies on sign languages showed that iconicity of signs contributes to lexical acquisition (e.g., Caselli \& Pyers, 2017 for American Sign Language; Sümer et al., 2017 for Turkish Sign Language; Woolfe et al., 2010 for British Sign Language). Thompson et al. (2013) showed that iconicity effects increased between age 2-4-years-old, supporting the idea that cognitive development and world knowledge allow children to rely on the iconic mapping of form to meaning (Meier et al., 2008). Together these studies suggest that iconicity of signs contributes to lexical acquisition (for an overview of the effect of iconicity on acquisition, see Ortega, 2017).

The effect of iconicity deserves attention of research due to conflicting evidence. On the one hand, there are studies showing the effect of iconicity diminishes with age (e.g., Massaro \& Perlman, 2017). On the other hand, there are studies showing that its effect increases with age (Thompson et al., 2013). Notably, the interaction between age and iconicity seems to be critical in our understanding the contribution of iconicity to language acquisition. If iconicity (the link between form and meaning) is mediated by cognitive development and language experience, the effect of iconicity would increase with age. This means that experience affects the child's ability to learn the form-meaning mapping of iconic signs and this would be related to age, which is a proxy of experience. In contrast, if iconicity relies on basic sensory motor associations between the form and the meaning, and it is not related to experience with language, age will not play a role (Perniss et al., 2010).

\section{Frequency of signs and sign language acquisition}

Frequency represents item-specific characteristics, or how often a word/sign is used in a given language. Its influence on language acquisition is beyond cognitive 
abilities as it refers to the input to which a child is exposed, suggesting that higher frequency words/signs have higher baseline activation that affects acquisition (Degani et al., 2019; Gollan et al., 2008).

It has been shown that the acquisition of lexical items is positively correlated with the frequency of these items in child-directed speech (e.g., Edwards et al., 2015) and in language use (Perry et al., 2018). For example, lexical items like "baby" and "ball" are acquired earlier than "coffee" and "computer," as the frequency of the words "baby" and "ball" is higher in child-directed speech. However, not all types of words are equally affected by frequency of usage. Closed-class (function) words (e.g., pronouns, prepositions, articles) are highly frequent, but have a negative correlation between frequency and child's lexical production (Braginsky et al., 2016; Goodman et al., 2008); that is, parents produce them frequently, but children master them later than other words.

The effects of frequency of use on the acquisition of lexical items change during child development (Goodman et al., 2008). The effect of frequency is also mediated by children's chronological age and vocabulary size, such that correlations with frequency become more pronounced after the first 100 words. Thus, the effects of frequency are sensitive to grammatical category and change over early language development.

Studies evaluating the effect of sign frequency in sign languages have come to contradictory conclusions. In one influential paper, Thompson et al. (2013) reported no effect of sign frequency, but subsequent studies in other sign languages do report a robust effect of frequency (Caselli \& Pyers, 2017 for American Sign Language; Sümer et al., 2017 for Turkish Sign Language). Whereas the term "familiarity" was used by Thompson et al. (2013) and the term "frequency" was chosen by Caselli and Pyers (2017), the two terms are closely linked (Vinson et al., 2008). Both studies operationalized their terms similarly by asking native adult signers to rate the frequency of the signs. Thus, the contradictory findings cannot be explained by the methodology of collecting frequency ratings.

Previous studies on sign languages have used a subjective index of frequency in adult-directed speech using ratings by fluent signers (Caselli \& Pyers, 2017; Sümer et al., 2017; Thompson et al., 2013). Although frequency in child-directed speech better predicts acquisition (Goodman et al., 2008; Hansen, 2017), these data are not available for any sign language, including in ISL.

To sum up, previous studies on sign language bring inconclusive evidence on the effects of iconicity and frequency on vocabulary acquisition. The current study aimed to contribute to this ongoing debate by investigating a sign language, that is, ISL, for which no vocabulary tools are available and no acquisition data have been previously reported.

\section{The current study}

The current study was devised to develop an ISL-CDI ${ }^{3}$ assessment tool and to explore vocabulary development in the sign modality of children who acquire ISL. We aimed to assess the effects of iconicity and lexical frequency on vocabulary acquisition in ISL of bimodal-bilingual children. With this aim in mind, we 
conducted two preliminary studies to obtain iconicity ratings from sign-naïve Hebrew-speaking adults (Study 1A) and lexical frequency ratings from native ISL signers (Study 1B).

In Study 2, following previous literature on vocabulary development of sign languages (see the "Introduction" section), it was hypothesized that age, iconicity, and frequency will uniquely contribute to vocabulary development in ISL. Moreover, it was predicted that the effects of iconicity and frequency will increase with age, and will show interaction of age and iconicity and age and frequency.

\section{ISL-CDI adaption materials}

The process of adapting the Hebrew CDI to ISL-CDI was conducted in two stages. Permission to develop the ISL-CDI was obtained by the authors from the CDI Advisory Board at the beginning of the project (https://mb-cdi.stanford.edu/ adaptations.html). We adapted the current ISL-CDI instrument from the Hebrew-CDI (Gendler-Shalev \& Dromi, 2020), integrating the original two age range versions into one version of a CDI questionnaire.

The first stage included an adaptation of the Hebrew word list to ISL by a team of six ISL experts that included a linguist investigating ISL, a deaf native ISL signer, two ISL interpreters, a clinical linguist, and a speech and language pathologist who knows ISL and has clinical experience with signing toddlers. The team explored each sign translation for content validity, meaning that the items of the instrument represent the linguistic structure of ISL, in terms of lexical categories (Haug, 2011). For example, adjectives and adverbs were included in the same category as there is no clear distinction between them in ISL, action signs were used in adapting verb words to ISL. The proficiency of the team and the collaborative work also contributed to the content validity of the instrument. As can be seen in the following description, we included only lexical entries that are signed by one sign or a compound in ISL, excluding lexical entries in Hebrew that are translated to more than one sign. Going through the list of words of the Hebrew-CDI, we used the following criteria:

a. If two Hebrew lexical items had minor meaning differences in ISL (e.g., the words combination "who is it" versus "who") only one sign was used ("who is it" was excluded and only the item "who" was included in ISL). In addition, Hebrew words combinations that are represented by a single sign in ISL were included (e.g., "I want" was included as WANT).

b. In cases in which signs for nouns and signs that describe actions were similar, we chose the noun (e.g., the verb TO SWING was excluded and only the noun sign for SWING was included). The rationale for this choice was that toddlers' extended movements, representing verbs in ISL (Tkachman \& Sandler, 2013), are hard to be distinguished from short movements, representing nouns. However, in cases in which the difference is clear (e.g., COMB signed with one movement vs. TO COMB, signed with two movements), the two signs were left.

c. Hebrew words without ISL correlates were excluded from the list (e.g., "katar," meaning an engine of a train and the word "train" have the same sign in ISL). 
d. If two different Hebrew words had one shared translation, the more generic (common) translation was included (e.g., the words "maxbi," meaning to hide and "mitxabe," meaning to hide oneself are represented in one sign HIDE).

e. Body parts that are signed with pointing were excluded to prevent the inclusion of indexical points that could be considered less lexical and would not have been counted in the language productions of hearing children (though they might also be present in those children), following Woolfe et al. (2010).

f. If signs have dialectal variations (e.g., there are two signs for the lexical item carrot), we used the more common variation.

g. When Hebrew adjectives and nouns shared the same translation in ISL, the adjective, which is more basic and generic in Hebrew, was chosen (CLEAN vs. CLEANING).

h. In ISL, some adjectives that refer to humans are different from those that refer to objects. In these cases, two signs were included in the ISL-CDI list (e.g., BIG for boy and BIG for an object).

i. In ISL, some verbs that refer to humans are different from those that refer to things (objects, concepts, events, etc.). In these cases, two signs were included in the ISL-CDI list (e.g., TO LOVE [PERSON], TO LOVE [THING]).

j. When two Hebrew words were synonyms and appeared in the same row of the questionnaire representing one concept-word (e.g., "to see" and "to show") but in ISL these items are represented by two different signs, the two signs were added separately.

k. Classifier verbs (e.g., TO CLEAN A TABLE, TO CLEAN A WINDOW) and verbs that can be modified for agreement were included in their generic form.

The second stage included choosing videos of the gloss signs from the ISL dictionary (http://isl.org.il/en/home-page-2/) and filming the missing signs. The current version of the ISL-CDI includes 563 sign videos divided into 17 lexical semantic categories, equivalent to the Hebrew-CDI (e.g., animals, toys, and food). The video format has an advantage on the pen-and-pencil format. For a parent who fills in the questionnaire watching a sign video is equivalent to filling in the written format of a spoken CDI. In contrast, using a written format for a sign language questionnaire involves translations between the spoken gloss and the sign language when filling out the questionnaire. An equivalent example in spoken language would be filling out a CDI for English vocabulary while reading a list of translated Hebrew words.

\section{Study $1(A, B)$ \\ Method}

\section{Participants}

Study 1A: Iconicity ratings. Forty-one sign-naïve adults ${ }^{4}(27$ females and 14 males) who speak Hebrew as their native language $\left(M_{\text {age }}=32, S D=12\right.$, Min-Max: 21-67) completed an iconicity rating questionnaire of the ISL-CDI signs. The participants belonged to mid-high socioeconomic status as measured by their years of education $(M=14, S D=5$ Min-Max: 12-18). The rational for using ratings from naïve 
participants was to reduce specific language knowledge effects that are not related directly to iconicity. For example, initialized signs can be rated as highly iconic because the handshape is the finger-spelled counterpart to the first letter of the spoken language translation. Furthermore, folk etymology about iconic origins of signs might influence iconicity ratings in signers. For example, the sign GIRL in American Sign Language is signed with a curved movement of the thumb on the cheek. Folk stories suggest that this sign was created to represent the chinstrap of a girly hat (Caselli \& Pyers, 2017). The assumption was that collecting iconicity ratings from nonsigners would provide us with a cleaner measure of the visual similarity between a sign and its meaning.

Study 1B: Frequency ratings. Nineteen ISL native signers (14 females and 5 males) $\left(M_{\text {age }}=32, S D=8\right.$, Min-Max: 23-46) rated the frequency of ISL signs. All participants were exposed to ISL from birth and grew up in a signing home with one or two signing parents. They were from different areas of Israel (north, center, and south), representing different signing communities. They were matched with the participants in Study 1A in belonging to a mid-high socioeconomic group, as measured by years of education $(M=14, S D=2$, Min-Max: $12-20)$.

\section{Procedure}

Study 1A: Iconicity ratings

Following Caselli and Pyers (2017), the hearing sign-naïve participants rated the iconicity of $554^{5}$ ISL signs. Each video sign was presented with its translation to Hebrew and the participant rated it on a scale of 1-7 (1-absolutely noniconic and 7-very iconic). The instructions were given in a written form prior to the task: "Sign languages tend to be iconic. That is, sometimes the shape of the sign resembles the shape of the object or entity in reality, or the movement of the sign is reminiscent of the action that the sign represents. Sometimes the sign is arbitrary and not-iconic. This means no connection between the sign and the concept it represents. Our scale ranges from 1 to 7 , where 7 represents the highest degree of iconicity, and 1 represents the lowest iconicity size." Participants watched the ISL-CDI videos and ratings were recorded in a digital form for responses.

\section{Study 1B: Frequency ratings}

The deaf native signers rated the frequency of 563 ISL signs presented to them on a scale of 1-7 (1-very rare; 7-very frequent) (Caselli et al., 2017; Vinson et al., 2008). Each video of an ISL sign was presented alongside a digital form for responses. Instructions were given in written Hebrew prior to the task. The English translation of these instructions was: "The purpose of this questionnaire is to rate signs according to their frequency of use. How frequent the sign is used daily. Our scale ranges from 1 to 7 , where 7 represents the highest frequency, and 1 represents the lowest frequency."

Each task (iconicity rating and frequency rating) took between $60-90$ minutes to complete. 


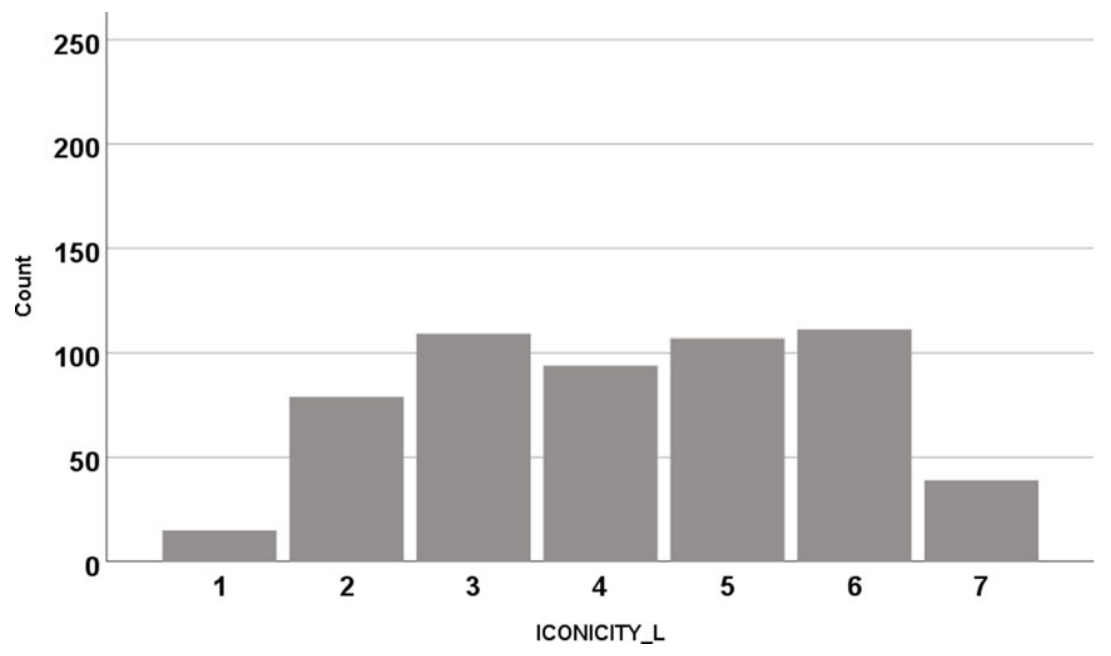

Figure 1. Distribution of signs per iconicity level.

\section{Results}

Study $1 A$ : Iconicity ratings

Mean iconicity ratings for the 563 ISL signs varied between 1.2 and 6.9 (see Figure 1 for the distribution of signs per Iconicity level). Fifty-six percent of the ISL-CDI signs were rated as highly iconic, that is, they received a score higher than a four on the 7-point scale (e.g., NO, PUSH, SLEEP, SMILE, TELEPHONE).

Within the 17 different lexical semantic categories, the categories of pronouns $(M=5.80, S D=0.76)$ and prepositions of places $(M=5.83, S D=1.00)$ received the highest iconicity ratings, while the category of people $(M=2.57, S D=1.31)$ received the lowest iconicity ratings (e.g., UNCLE, KINDERGARDENTEACHER) (Table 1). Most signs in the pronoun category are signed by pointing to the referent direction (e.g., $I$ is signed by pointing to self). In the category of prepositions of places, most signs are signed with the two hands representing the meaning of the preposition relationship (e.g., $\mathrm{ON}$ is signed with open flat handshape and the dominant hand is placed on the back of the nondominant hand with palms facing down; for IN, the dominant hand is produced with fingers together touching the thumb held [in a " $c$ " shape] and the dominant hand moves inside the nondominant hand within the neutral signing space).

\section{Study 1B: Frequency ratings}

Mean frequency ratings varied between 2.3 and 6.7 (see Figure 2 for the distribution of signs per frequency level). Ninety-eight percent of the ISL-CDI signs in the ISL-CDI were rated as highly frequent (e.g., DOG, CAR, FOOD), that is, they received a score higher than four on a 7-point scale.

We further tested if there were any differences in frequency ratings across different lexical semantic categories in the ISL-CDI (see Table 1). The category of body parts received the lowest frequency ratings $(M=5.19, S D=1.06)$ this 
Table 1 . Mean iconicity and frequency rating per lexical semantic category

\begin{tabular}{|c|c|c|c|c|c|}
\hline & \multicolumn{3}{|c|}{ Iconicity } & \multicolumn{2}{|c|}{ Frequency } \\
\hline & $n$ & Mean & SD & Mean & SD \\
\hline Animals & 43 & 4.22 & 1.05 & 5.25 & 1.10 \\
\hline Transportation & 13 & 4.06 & 1.58 & 6.15 & .87 \\
\hline Toys & 21 & 4.46 & 1.59 & 5.63 & 1.09 \\
\hline Food & 70 & 3.01 & 1.27 & 6.00 & .83 \\
\hline Clothing & 31 & 4.65 & 1.49 & 5.63 & 1.07 \\
\hline Furniture & 33 & 3.50 & 1.46 & 5.93 & 1.03 \\
\hline Home & 73 & 4.90 & 1.41 & 5.77 & .80 \\
\hline Outside and places & 29 & 3.53 & 1.36 & 5.88 & .91 \\
\hline People & 21 & 2.57 & 1.31 & 6.00 & .73 \\
\hline Greetings & 21 & 4.39 & 1.71 & 6.44 & .82 \\
\hline Action signs & 101 & 5.01 & 1.33 & 6.13 & .62 \\
\hline Adjectives & 50 & 3.98 & 1.46 & 6.31 & .39 \\
\hline Time & 13 & 3.99 & 1.82 & 6.72 & .23 \\
\hline Pronouns & 10 & 5.80 & .76 & 6.46 & .48 \\
\hline Question words & 11 & 3.91 & 1.56 & 6.42 & .34 \\
\hline Prepositions place & 14 & 5.83 & 1.00 & 6.23 & .34 \\
\hline Body Parts & 9 & $\mathrm{n} / \mathrm{a}^{\star}$ & $n / a^{*}$ & 5.19 & 1.06 \\
\hline Total & 563 & 4.23 & 1.58 & 5.97 & .86 \\
\hline
\end{tabular}

${ }^{*} \mathrm{n} / \mathrm{a}=$ not applicable.

Note: In ISL many signs for body parts are signed with pointing and were excluded from the pretested version of the test. The nonpointing signs were added to the questionnaire only after iconicity ratings were collected. Thus, this category is not tested as part of the iconicity effect on acquisition.

category did not include body parts that were signed by using a pointing (see the "ISL-CDI Adaption Materials" section for more details) and the category of time words received the highest frequency ratings $(M=6.72, S D=0.23)$. As stated previously, these ratings are based on frequency of use by adults, not in childdirected signs. Pearson correlational analysis showed that there were no significant correlations between iconicity and frequency ratings $(r=.073, \mathrm{n}=554, p=.088)$.

\section{Discussion of study 1a: iconicity}

When exploring iconicity across different lexical categories, the categories of pronouns and prepositions of places received the highest iconicity ratings. In contrast, the category of people received the lowest iconicity ratings in ISL, similarly to iconicity examples from British Sign Language (Vinson et al., 2008).

An interesting difference between the current study and other studies is the pattern of iconicity ratings. In the current study participants rated the signs across the 


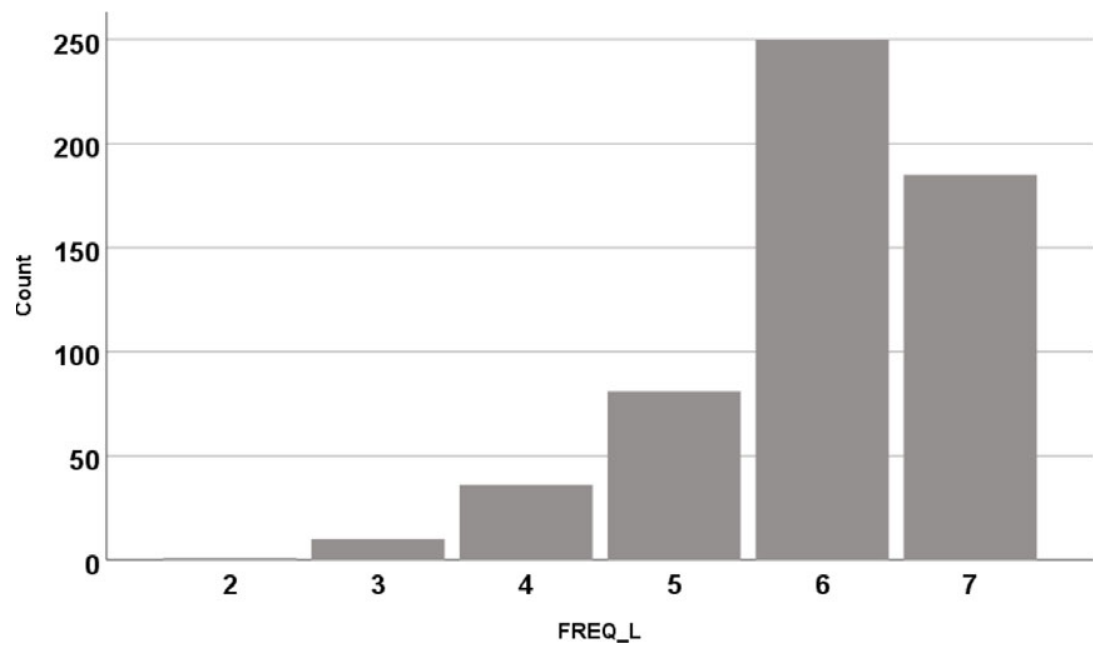

Figure 2. Distribution of signs per frequency level.

scale as can be seen in Figure 1. In Vinson et al. (2008), iconicity rating were bimodally distributed, and in Tasci et al.'s study (2017) deaf participants gave higher iconicity ratings than hearing nonsigners. One explanation for this difference between these studies can be the profile of the participants (Occhino et al., 2017). In Vinson et al.'s study (2008), the participants were native signers, in the current study they were hearing sign naïve adults. These gaps suggest that knowing a language might push raters toward stricter boundaries of iconicity or to higher ratings. In the current study there were significant correlations between the sign-naïve participants and the native ISL signers $(r=.71, p<.001)$. The different pattern of iconicity in hearing adults and native signers rating awaits future studies.

Support for the effect of language knowledge and world knowledge on iconicity comes from a study that tested the ability of hearing adults and children who did not know sign language to guess the meaning of iconic signs from the ISL-CDI list (Ali \& Farage, 2017). The study included 30 video signs from the ISL-CDI with high iconicity rating of 5.8-7.0. Whereas adults guessed in average $78 \%$ of the signs, children guessed only $29 \%$ of these signs with significant difference between the groups. It suggests that having more experience with language and world knowledge may result in more pronounced effects. Thus, the effects of language patterns and world knowledge and their influence on language acquisition await future research. We further explored the relationship between iconicity and age and the contribution of iconicity to language acquisition in Study 2.

\section{Discussion of study $1 \mathrm{~b}$ : frequency}

Most signs (98\%) of the ISL-CDI were frequent signs based on the ratings of native signers. Note that all ISL-CDI signs are expected to be acquired at early age (up to 36 months). These results are in line with previous studies showing that early-acquired vocabulary is frequent in the language (Braginsky et al., 2016; Diessel, 
Table 2. Demographic data per group

\begin{tabular}{lccc}
\hline & & $\begin{array}{c}\text { Younger Group } \\
(\mathrm{n}=22)\end{array}$ & $\begin{array}{c}\text { Older Group } \\
(\mathrm{n}=12)\end{array}$ \\
\hline Chronological Age (months) & $M(S D)$ & $22(9)$ & $69(13)$ \\
& $M I N-M A X$ & $8-36$ & $46-86$ \\
\hline Age at Diagnosis (months) & $M(S D)$ & $0.3(1.3)$ & $0.2(0.4)$ \\
& $M I N-M A X$ & $0-6$ & $0-1$ \\
\hline Hearing Age (for hearing aid users) (months) & $M(S D)$ & $7.6(2.9)$ & $6.3(3.7)$ \\
& $M I N-M A X$ & $3-12$ & $2-12$ \\
\hline Hearing Age (for cochlear implant users) (months) & $M(S D)$ & $15.8(5.8)$ & $14.2(2.9)$ \\
& $M I N-M A X$ & $10-26$ & $10-18$ \\
\hline-3 & $M(S D)$ & $29(32)$ & $74(34)$ \\
\hline Hearing Function & $M I N-M A X$ & $0-100$ & $0-100$ \\
\hline (IT-MIAS in \%) & $M$ \\
\hline
\end{tabular}

* For children with hearing aids, hearing age was calculated based on age of hearing aid fitting. ${ }^{* *}$ For children using cochlear implants, hearing age was calculated based on cochlear implant activation. Cochlear implantation is recommended, when no sufficient gain in hearing function with the hearing aids is observed.

2007; Goodman et al., 2008). Children are sensitive to external variables, that is, how frequently words appear in their input: frequent words are acquired earlier than rare words (Goodman et al., 2008). Similar findings are shown also for American Sign Language (Caselli \& Pyers, 2017).

Finally, there was no correlation between frequency and iconicity, suggesting that each of these two factors can independently facilitate acquisition. We examined this question in Study 2.

\section{Study 2}

Study 2 tested early acquisition of ISL vocabulary based on the ISL-CDI parental questionnaire and explored the relationship between age, iconicity, and frequency of vocabulary development in the sign modality (ISL) of bimodal-bilingual children born to native signers.

\section{Method}

\section{Participants}

Thirty-four bimodal-bilingual deaf children $\left(M_{\text {age }}=39\right.$ months, $S D=25$, Min-Max: 8-86), acquiring ISL as their native language, participated: 22 younger children and 12 older children (Table 2). The sample was comprised of 20 boys and 14 girls (in the younger group: 14 boys and 8 girls; in the older group: 6 boys and 6 girls). The rational for testing older children on the ISL-CDI questionnaire was motivated by the need to identify the age of ceiling scores on the instrument. All children had severe to profound hearing loss, they all had two deaf parents, and ISL was the home language. None of them had any neurological disorders based on parental report. Families were recruited across the country (north, center, and south) using personal contacts in the deaf community. The sample although 
Table 3. Exposure to ISL and Hebrew in the home setting per group (rating range 1-7)

\begin{tabular}{cccccccc}
\hline & \multicolumn{2}{c}{ ISL } & & \multicolumn{2}{c}{ Hebrew } \\
& & $\begin{array}{c}\text { Younger Group } \\
(\mathrm{n}=22)\end{array}$ & $\begin{array}{c}\text { Older Group } \\
(\mathrm{n}=12)\end{array}$ & & $\begin{array}{c}\text { Younger Group } \\
(\mathrm{n}=22)\end{array}$ & $\begin{array}{c}\text { Older Group } \\
(\mathrm{n}=12)\end{array}$ \\
\hline $\begin{array}{c}\text { Exposure by } \\
\text { mother }\end{array}$ & $M(S D)$ & $6.1(2.4)$ & $5.4(1.8)$ & & $4.7(1.7)$ & $5.4(1.7)$ \\
\cline { 1 - 2 } $\begin{array}{c}\text { Exposure by } \\
\text { father }\end{array}$ & $M(S D)$ & $6.1(2.3)$ & $6.0(1.7)$ & & $4.5(1.5)$ & $5.0(2.0)$ \\
\hline $\begin{array}{c}\text { Exposure by } \\
\text { siblings }\end{array}$ & $M(S D)$ & $4.7(2.4)$ & $4.7(2.1)$ & & $3.5(2.3)$ & $4.7(2.5)$ \\
\hline
\end{tabular}

small in size, represents $0.3 \%$ of the community (based on estimation of 10,000 members in the community; Sandler, 2018). All families were from middle socioeconomic status as measured by mother's years of education $(M=13$ years, $S D=2$, Min-Max: 10-17) and father's education ( $M=13$ years, $S D=1$, Min-Max: 10-16). All participants were diagnosed as having hearing impairment before age of 1 month (Table 2) due universal newborn hearing screening practice in Israel (Gilbey et al., 2013). Children started intervention during the first months after birth. In the younger group, 5 children had two cochlear implants, 16 children had two hearing aids, and 1 child was in the process of hearing aids fitting. In the older group two children had one cochlear implant, seven children had two cochlear implants, and three children had two hearing aids. Intervention included both languages (Hebrew and ISL) and hearing training. IT-MAIS scores (Ben-Itzhak et al., 2014) (Table 2) show the range of hearing capacity of the group. As expected, hearing function scores on the IT-MAIS were higher for the older group compared with the younger group because the children in the older group had more hearing experience. This finding is in line with previous studies (e.g., Novogrodsky et al., 2018). With age, children who use functional hearing devices (hearing aids and cochlear implants) and receive hearing intervention progress in their hearing function capacities, which contributes to spoken language acquisition. This might affect the current group's spoken vocabulary acquisition. However, this is beyond the scope of the current study.

Table 3 presents information on the exposure to ISL and Hebrew in home setting (on a scale of 1-7). The results of the parental questionnaire demonstrate that children are exposed to both languages, yet they get more exposure in ISL as compared to Hebrew and this is especially evident in the younger group.

Looking into the patterns of exposure at educational settings based on parental reports, in the younger group, most children (20 out of 22 ) have access to ISL with signed Hebrew and spoken Hebrew. In the older group, most children (10 out of 12) are exposed to ISL with signed Hebrew and spoken Hebrew. However, only 10 parents out of 22 in the younger group and 7 out of 12 in the older group indicated that their children are exposed to ISL from native signers at the educational settings. 
The characteristics of the current sample of native signers support that these children are early bimodal-bilinguals. With early hearing screening and the use of new technology, the bimodal-bilinguals in the current sample differ from the samples reported in earlier studies of 20 years ago where the spoken language was acquired latter by deaf children born to deaf parents during school age through print (reading and writing).

\section{Materials}

The ISL-CDI questionnaire adapted from the Hebrew-CDI (Gendler-Shalev \& Dromi, 2020) was used, as described in Study 1.

A background questionnaire was designed for bimodal-bilingual children based on questionnaires previously developed for parents of deaf children (Caselli, 2016), for assessing hearing function of children with hearing impairment (Ben-Itzhak et al., 2014), and for evaluating the grammatical stage of the child (GendlerShalev \& Dromi, 2020). The questionnaire includes 40 questions on demographic information, early child's language and developmental milestones, child's hearing function, and information on language use (including ISL and Hebrew).

Naturalistic data (a Lego game activity, spontaneous conversation, interaction with a book, and a structured elicitation task) were available for 12 children. Data were glossed using ELAN (ELAN, 2018) software by two interpreters and with the help of a deaf native ISL signer, all three were part of the ISL-CDI development team. Average type/token ratio scores were calculated. The scores were correlated with the ISL-CDIs of these 12 children as part of the ISL-CDI validity testing.

\section{Procedure}

Deaf parents received a link to the ISL-CDI video instrument online and another link to a digital form for responses. Only production data were collected for this study. A research assistant, who is a deaf native ISL signer, gave instructions in ISL to each parent during a meeting, which included filling out a background questionnaire in addition to the ISL-CDI questionnaire.

\section{Results}

The validity of the ISL-CDI

First, we analyzed the ISL-CDI data across the two groups of participants. The results showed strong positive correlations between productive ISL vocabulary (ISL-CDI) and Age $(r=.852, \mathrm{n}=34, p<.001)$ (see Figure 3). Furthermore, ISL-CDI scores significantly correlated with parental ratings of children's ISL skills as rated in the parental background questionnaire $(r=.695, \mathrm{n}=34, p<.001)$, and there were strong correlations between parental rating and ISL size even when age was controlled for $(r=.549, \mathrm{n}=34, p=.001)$.

To further explore the validity of the ISL-CDI questionnaire, we correlated the ISL-CDI scores of 12 of the participants for whom we collected naturalistic data and type/token ratio scores were available. Results showed significant correlations between ISL score and type/token ratio scores $(r=.603, n=12, p=.038)$. 


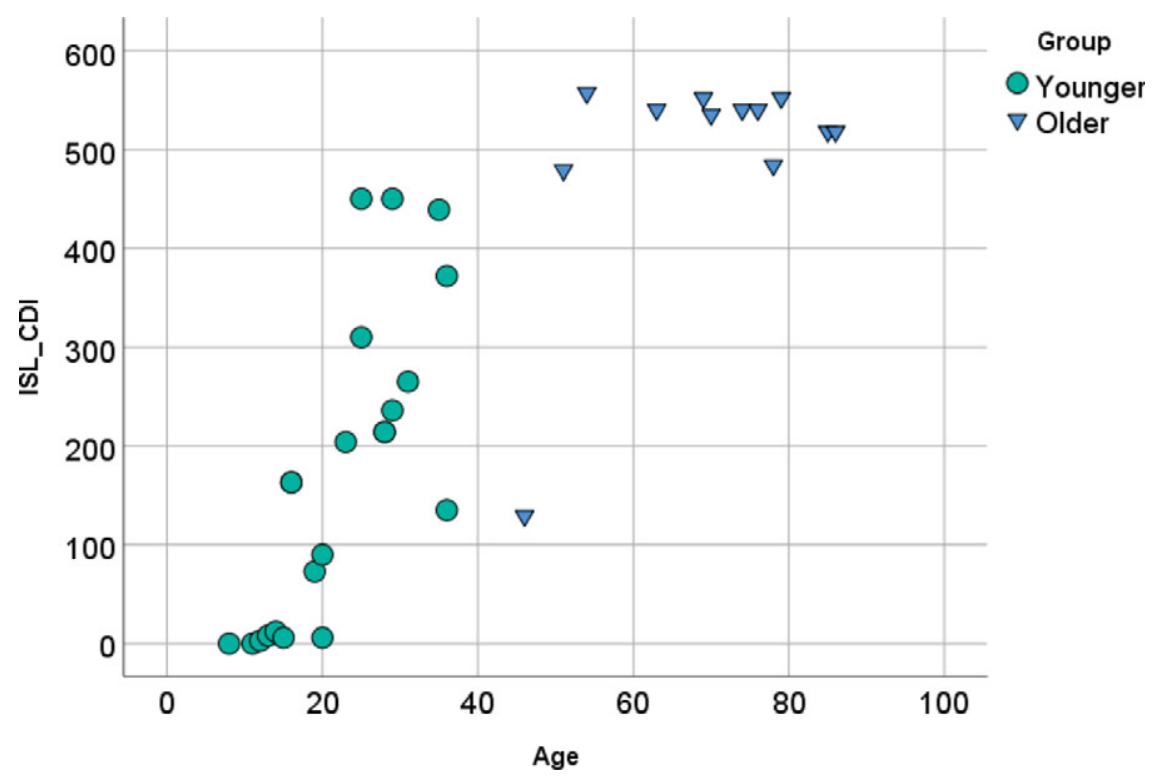

Figure 3. Scatterplots of ISL-CDI scores per child's age in months $(n=34)$.

These three measures support the concurrent validity of the ISL-CDI questionnaire for assessing vocabulary capacity.

\section{Descriptive statistics}

Children's ISL-CDI scores (productive vocabulary) varied between 0 and 557 ( $M=286, S D=211)$, out of a total of 563 ISL signs. In the younger age group (age range: 8-36 months), children scored between 0-460 $(M=173, S D=156)$ (Figure 3). For example, one child, aged 11 months, was reported to use no signs, whereas another child, aged 8 months, was reported to use one sign and a 15-month-old child was reported to use seven signs. These results reflect a variation in vocabulary size within this age group. In the older age group (age range: 46-86), most children showed a ceiling effect, meaning that they had acquired nearly all of the 563 signs of the ISL-CDI $(M=495, S D=118$, Min-Max: 129-557) (Figure 3).

Two signs were produced by above $90 \%$ of the children: LIGHT (94\%) and BYE-BYE (91\%), suggesting that these are the earliest acquired signs. Eleven signs were produced by $80 \%$ of the children and above. These signs represent the categories of family members (e.g., MOTHER, FATHER), food (e.g., WATER, FOOD), animals (e.g., FISH, DOG, BIRD), toys (e.g., BALL), greeting (e.g., HI), action signs (e.g., SLEEP), and situations and events (e.g., MORE).

Following the analysis of Frank et al. (2019), we further ran model fit curves for the proportion of each semantic category produced by each child as a function of the proportion of vocabulary size of each child (Figure 4). Figure 4 shows areas where the data deviate from the pattern of category acquisition predicted by random item sampling. The size of the region above versus below the dotted diagonal indicates 

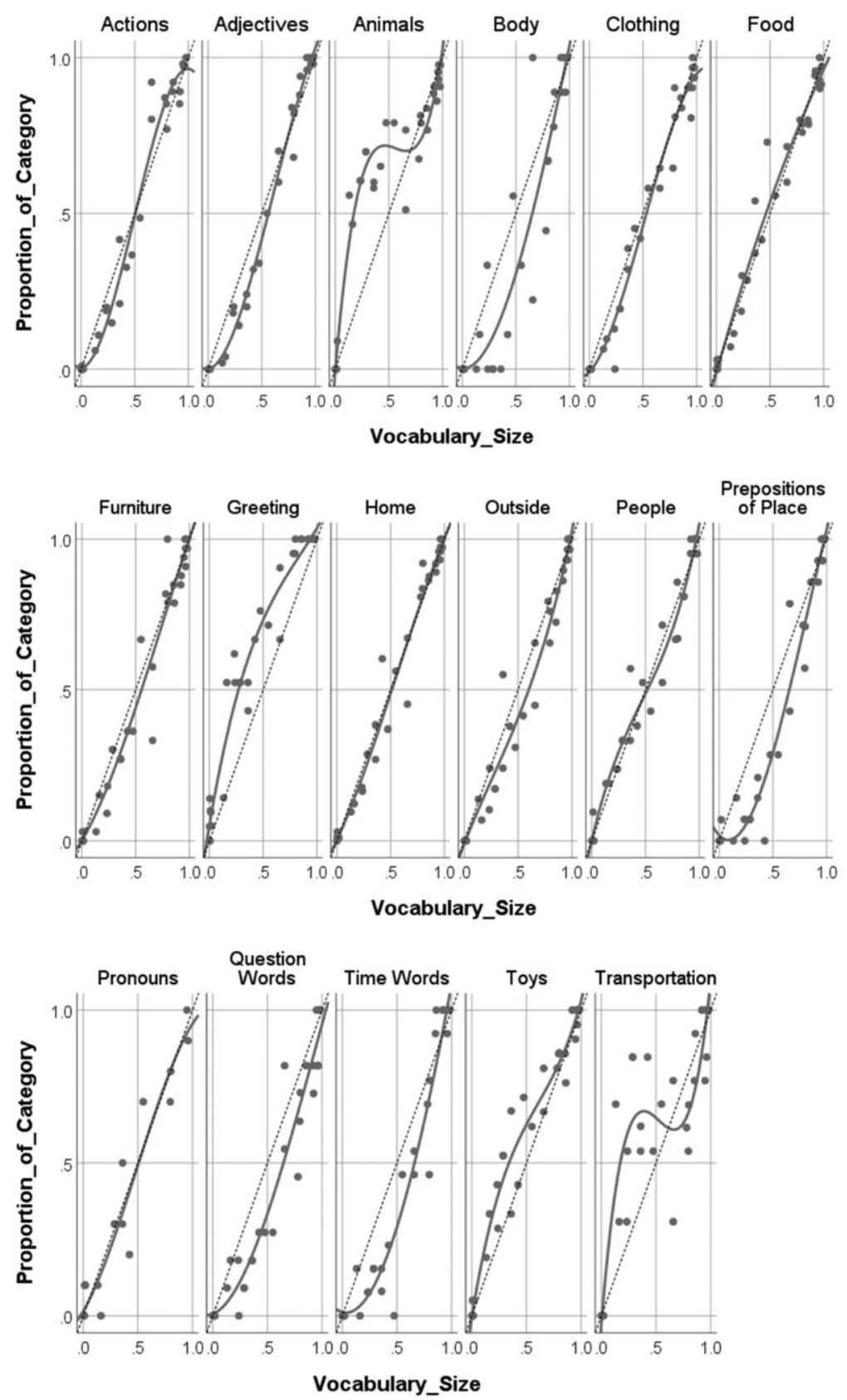

Figure 4. Model fit curves for proportion of each semantic category produced by each child as a function of the proportion of vocabulary size of each child. 
Table 4. Results of the fixed effects of the binominal mixed-effects logistic regression (the results for the fixed coefficients see in Appendix 1)

\begin{tabular}{lcccc}
\hline Fixed Effects & & & & \\
\hline Source & $\mathrm{F}$ & $\mathrm{df1}$ & $\mathrm{df2}$ & Sig. \\
\hline Corrected Model & 40.495 & 23 & 18788 & .000 \\
\hline ICONICITY & 2.819 & 6 & 18788 & .010 \\
\hline FREQUENCY & 2.501 & 5 & 18788 & .029 \\
\hline Age & 93.741 & 1 & 18788 & .000 \\
\hline Age ${ }^{*}$ ICONICITY & 2.455 & 6 & 18788 & .022 \\
\hline Age ${ }^{*}$ FREQUENCY & 14.953 & 5 & 18788 & .000 \\
\hline
\end{tabular}

(a)

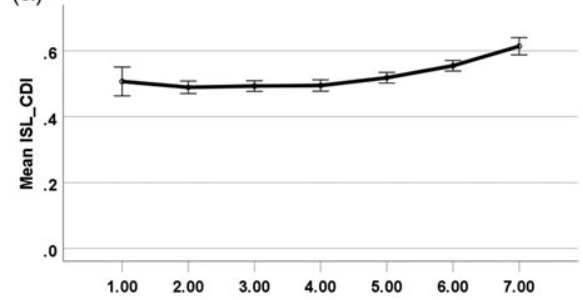

(b)

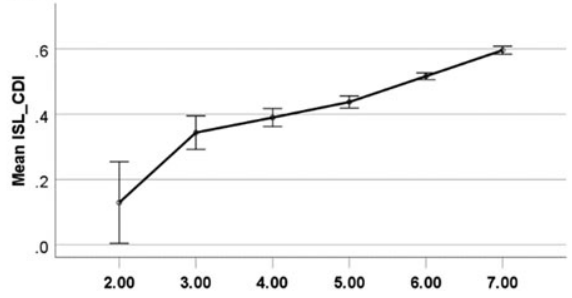

Figure 5. ISL-CDI scores (\% out of the total score) per (a) iconicity and (b) frequency band. Error bars present $95 \% \mathrm{Cl}$.

over- versus undersampling for a particular semantic category. Interestingly, the categories of animals, greeting, toys, and transportation are overrepresented in early stages of vocabulary acquisition, while the categories of preposition of places, body parts, question words, and time words are underrepresented.

\section{Effects of age, iconicity, and frequency on sign acquisition}

Secondly, we evaluated the effects of age, iconicity, and frequency on acquisition of vocabulary in ISL. We analyzed the data using a binominal mixed-effects logistic regression model. Given the binary nature of our dependent variable for ISL acquired signs (child produces the sign $=1$, child does not produce the sign $=0$ ), participants and items were included as random factors. The inclusion of these two variables enabled us to account simultaneously for child-specific and item-specific variability and allowed for generalization beyond both the sample of children and the set of vocabulary items. Three fixed effects were included into the model: iconicity (mean ratings), frequency (mean ratings), and age (months). We also included Age Frequency and Age Iconicity interactions. The analysis (Table 4) showed significant main effects of age, iconicity, and frequency. The findings showed that with increasing age children were likely to produce more signs. 
(a)

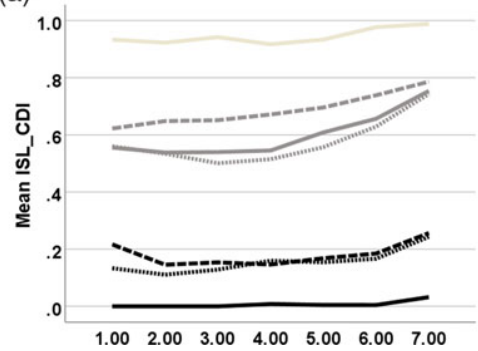

(b)

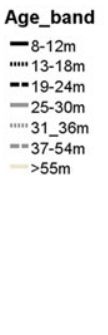

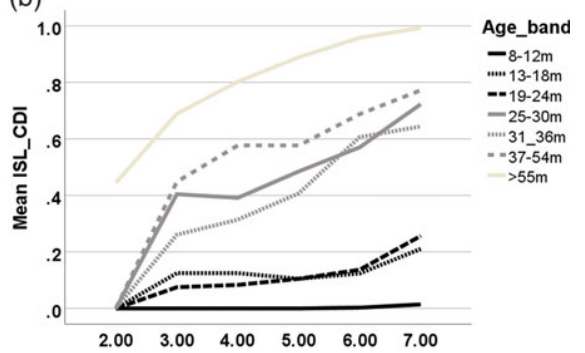

Figure 6. ISL-CDI scores (\% out of the total score) per (a) iconicity and (b) frequency band. Error bars present $95 \% \mathrm{Cl}$.

Children were more likely to produce signs with higher rather than low iconicity ratings, and signs with higher rather than low frequency ratings (see Figure 5). The model also yielded significant Age ${ }^{\star}$ Frequency and Age ${ }^{\star}$ Iconicity interactions, pointing at different effects of frequency and iconicity over the course of child's language development.

For the ease of interpretation of the Age ${ }^{\star}$ Frequency and Age Iconicity interactions, we divided children into several age bands (see Figure 6). Visual inspection of the Age ${ }^{\star}$ Iconicity interaction (Figure 6a) suggests that in the older age band group (> 55 months) there was a ceiling effect. In the younger age bands (8-24 months) only words with the highest iconicity ratings (closer to 7) were likely to be produced, whereby in the group of children of the middle band (25-54 months) the effect of iconicity is present: signs that are more iconic more likely to be produced. However, the results for the Age Iconicity interaction must be interpreted with a degree of caution, as the interaction was not robustly significant.

Turning to the Age ${ }^{\star}$ Frequency interaction, visual inspection of the data (Figure 6b) suggests that the effect of frequency is robustly present after the age of 24 months, meaning that signs that are more frequent in the lexicon are more likely to be produced. Furthermore, in the younger group the effect is present yet, it is less robust as compared to older children.

\section{General discussion}

Our study was devised to develop the ISL-CDI assessment tool to explore the acquisition of sign production in ISL. The current study is the first study to investigate ISL acquisition. Secondly, it was devised to assess the role of age, frequency, and iconicity on early vocabulary acquisition in the sign modality of bimodalbilingual children. The study aimed to add new findings to the conflicting evidence on the role of iconicity and frequency in sign language acquisition. We discuss the findings for early sign production in ISL and compare the results of the current study to previous findings of sign and spoken languages. We then discuss the relationship between age, frequency, and iconicity as shown in the current ISLCDI data. 


\section{Early ISL production}

The current study described the development of an ISL-CDI parental questionnaire, which was carefully adapted from Hebrew to ISL. The findings support the validity of the newly designed tool for assessing ISL vocabulary development in native signing toddlers. This was shown by three measures. First, there were significant correlations between age and ISL-CDI scores, reflecting the expected vocabulary growth over time. These results reiterate findings for spoken languages (Bavin et al., 2013) as well as previous results for sign languages (Caselli \& Pyers, 2017; Sümer et al., 2017; Woolfe et al., 2010). In addition to correlations between age and ISL-CDI scores, there were significant correlations between parental ratings of children's ISL skills (based on the parental background information questionnaire) and children's ISL-CDI scores. Importantly, there were significant correlations between parental ratings and vocabulary scores even when age was controlled for. Moreover, there was a significant correlation of type/token ratio from naturalistic sign production and children's ISL-CDI scores for a subgroup of 12 children. Together these three measures (age, parental reports, and child actual production) support the validity of the newly developed ISL-CDI questionnaire.

The current results are in line with the growing literature supporting the validity of the CDI as a measure of children's lexical development across different sign languages (Caselli \& Pyers, 2017; Sümer et al., 2017; Woolfe et al., 2010). In addition, it supports previous studies showing that parental ratings are a reliable measure of assessing children's language skills (Bavin et al., 2013).

The small sample of participants neither allows us to evaluate the effect of age of acquisition per sign, nor enables us to develop norms for the number of signs per age group. Yet, with this limitation in mind, two similarities to spoken language are yielded nevertheless: wide variability of children's vocabularies at initial language acquisition stages and age of onset of signs. Our results support findings of a wide variability in the reported vocabulary size of children at initial language acquisition stages (Fenson et al., 2000a). While some children between 1 to 2 years old produced only a small number of signs, others had a vocabulary of 100-200 signs. The size of vocabulary before the age of 12 months in the current study resembles the findings for British Sign Language (Woolfe et al., 2010), and findings from spoken languages, suggesting that at this age children have less than 10 signs/words. Thirteen signs were not produced by any child aged 8-36 months. ${ }^{6}$ This finding has applied clinical implications. It suggests that if the ISL-CDI aims to measure vocabulary of children aged 12-36 months, these signs should be excluded.

Age of onset of signs is another important measure. Capirci et al. (2002) argued that when gestures are properly distinguished from signs, both speaking and signing children show comparable age of onset of communicative first word/sign around age of 12 months. In the current study, we asked parents to report only on sign production and the gesture part of the questionnaire was excluded. We believe that this process reduced confusion and overlap between gestures and signs in parental responses, resulting in a similar age of onset to the one reported by Capirci et al. (2002). Support for the assumption of comparable age of onset in sign languages can come from future studies that will explore the relationship between onset of 
sign and spoken languages, for example, sign scores (ISL-CDI) and spoken scores (Hebrew-CDI) of the same children.

It is important to note that whereas previous studies tested monolingual signers, the current study investigated the acquisition of the sign language in bimodalbilingual children. Language dominance shifts in bilingual speakers over the lifespan. In the current study bimodal-bilingual children were dominant in ISL, based on parental reports (as can be seen in Table 3). Yet, we might assume that with increased exposure to the spoken language, Hebrew, due to schooling, there might be a dominance shift to Hebrew (the Societal Language). This hypothesis needs to be tested in future longitudinal studies. Moreover, in the current study hearing function (as tested by IT-MAIS) was higher in the older children. Because there is evidence that hearing function affects positively the acquisition of spoken language (e.g., Novogrodsky et al., 2018), future studies need to assess the effect of hearing function on the acquisition and maintenance of the sign language of bilingual-bimodal children. The interactions between the sign and the spoken language in bimodal-bilingual children, including different childinternal and child-external variables await future studies.

Previous studies using the CDIs in a variety of spoken bilingual contexts have shown that children with dominant exposure to one of their languages have vocabulary sizes that are similar to those of monolingual speakers of the language (e.g., for German-English bilinguals, Junker \& Stockman, 2002; but see contradictory findings, Hoff et al. 2012). This comparison cannot be tested in our case because to the best of our knowledge most of deaf children in Israel grow up bimodal-bilingual from an early age. Yet, future studies need to investigate the acquisition of Hebrew and total conceptual vocabulary in bimodal-bilingual children as compared to their monolingual Hebrew-speaking peers. O'Toole et al. (2017) compared the vocabulary size of 250 bilinguals aged 24-36 months acquiring six different language pairs. Their findings emphasized the prominence of the CDI in the context of bilingual children to assess the child's home language. The authors argued that it allows clinicians to gain insight into the child's acquisition of a language the clinician does not know. In the case of bimodal-bilingual children, while the spoken language is usually known by clinicians and educators, their sign language knowledge is often limited. Thus, the importance of the current tool is in its ability to get a precise report for ISL. Armon-Lotem and Ohana (2017) suggested that both languages of a bilingual child should be taken into consideration to generate bilingual norms for that specific population, or use a conceptual vocabulary score and compare it to monolingual norms. In any assessment scenario, the CDI tool of a sign language is required as part of the assessment procedure of bimodal-bilingual children.

Interestingly, the characteristics of the different lexical semantic categories showed that children acquiring ISL produced more signs from certain categories in early stages of vocabulary acquisition. Signs that were produced by most of the children ( $80 \%$ and above) were from the following categories: greetings (HI, BYE-BYE), toys (BALL), and animals (FISH, DOG, BIRD). The current findings are in agreement with previous studies on other sign languages. For example, similar categories are also found in early signs of children acquiring American Sign Language: animals (e.g., DOG, CAT) and greetings (e.g., BYE) (Chen-Pichler, 2012). 
In contrast, the categories of question words, prepositions of places, and time words were underrepresented in early stages of vocabulary acquisition of toddlers in ISL. Many of the signs in these categories belong to closed-class (function) words/ signs that are reported to be acquired later (e.g., Goodman et al., 2008). Another category with underrepresented signs in early stages of vocabulary acquisition is body parts. This category requires an explanation as it is a common category in children's early vocabulary. In the current version of the ISL-CDI most body parts were excluded because they are signed by pointing. Following previous studies (e.g., Woolfe et al., 2010), this process aimed to reduce confusion between gestures and signs for the parents who filled out the questionnaire (for more details see method of Study 1). This resulted in a small number of body parts signs in the category that included rare signs (e.g., FACE, CHIN, NECK), which explains their underrepresentation in the early vocabulary.

\section{Effects of age, iconicity, and frequency in early sign production}

In this subsection, we discuss the three parameters that might potentially affect vocabulary acquisition in ISL: age, frequency, and iconicity. The parameter of age was discussed previously. Correlations between age and ISL-CDI scores support the concurrent validity of the ISL-CDI tool. In addition, the results suggest that similarly to other sign languages, as toddlers use a sign language, they acquire more signs from different lexical categories (Caselli \& Pyers, 2017; Sümer et al., 2017; Woolfe et al., 2010). Here we further discuss the interactions between age and iconicity, and age and frequency.

\section{Iconicity}

Our results suggest that the effect of iconicity increase with age in line with findings from spoken languages (Massaro \& Perlman, 2017; Maurer et al., 2006; Perry et al., 2018). For example, Maurer et al. (2006) compared toddlers aged 2.5 years and adults. They found that at this age children were sensitive to iconicity patterns of spoken nonwords. Similarly, in the current study, children aged 25-55 months (Figure 6a) showed an iconicity effect, while younger children did not (and older children showed a ceiling effect). Two contrastive accounts attempt to explain the influence of iconicity on language acquisition. One account suggests that if iconicity is mediated by exposure to real-world and contextual information, allowing children to grasp the link between form and meaning, age would influence its outcome. This assumption predicts that with age, the effect of iconicity increases. In contrast, if iconicity relies on basic sensory motor associations, it will not be mediated by real-world experience, and no interaction with age will be shown (Perniss et al., 2010). Our findings support the former hypothesis: the iconicity effect is mediated by development and real-world experience.

In studies of sign languages, the role of iconicity was shown for older children aged 10-12 years in a picture/sign matching task by faster responses for highly iconic signs compared with less iconic signs (Ormel et al., 2009). Similar effects were found previously also for younger children aged 2-4 years (Thompson et al., 2013). Furthermore, within this age group (2-4 years), older children showed a larger 
iconicity effect. Importantly, when testing the iconicity effect in children younger than 2 years old, the iconicity affect is not evident. For example, in a longitudinal study of 13 native signers (median age of 10 months at outset of study), only one third of the first 10 signs the children acquired were iconic signs and the proportion of iconic signs was similar at age 18 months (Orlansky \& Bonvillian, 1984). Moreover, the effect of age is also shown in the iconic gesture use among hearing children. For example, Özçalişkan et al. (2014) found that children use iconic gestures conveying action meanings only after they begin to acquire the verb system underlying their language. Finally, the role of iconicity is also reflected in sign language input that children receive. For example, in a longitudinal case study that followed two bimodal-bilingual hearing children's acquisition of ISL and Hebrew from the age of 10 to 40 months, the "Motherese" input was characteristic with exaggerated iconic production (Fuks, 2018).

The current results expand our knowledge on the iconicity effect showing that the iconicity effect is more robust after the age of 24 months. While we showed a larger iconicity effect for later acquired signs compared to first signs produced by native signers, the most common case of sign language acquisition is among deaf children born to parents who do not sign. Deaf children born to hearing parents who do not sign are considered to have delayed exposure to language, signed or spoken. The delay in sign exposure is due to the lack of input from the environment that does not sign, and the delay in spoken language is due to the hearing impairment (Henner et al., 2018). It should be kept in mind that when acquiring sign language, deaf children born to hearing parents are older and have mature cognitive abilities and more exposure to real-world experience, thus a large iconicity effect for the first signs might be found for this group of children. This question should be addressed in future studies. Another question remains open regarding the iconicity effect across different semantic categories. Whereas the current analysis explored the iconicity effect based on item ratings, it will be interesting to explore in future studies the effect of iconicity on the acquisition of different semantic categories. For example, the category of pronouns received a high iconicity rating but showed equal proportion of use as a function of the proportion of vocabulary size. Looking at the relative representation of pronouns in early vocabulary of ISL acquires, this semantic category is acquired in a parallel rate along the growth of vocabulary size. The gap between these two findings awaits future studies that will focus on exploring different semantic categories. The last point that we would like to raise with regard to the iconicity effect relates to the iconic mapping process (Taub, 2001). It is assumed that different types of iconic mappings may facilitate acquisition (Ortega, 2017). In the current study, we tested iconicity as a holistic concept and showed that there is an iconicity effect on vocabulary acquisition and that this effect increases with age. However, the nature of this effect at different ages might be modulated by different iconicity parameters. The way iconicity leverages acquisition remains unclear based on the current data and needs to be further explored in future studies. To summarize, the current findings provide novel evidence from a sign language not previously tested that iconicity is central in vocabulary acquisition of sign languages and that it functions as a bridge between linguistic form and human experience (Thompson et al., 2013). 


\section{Frequency}

Our results showed that iconicity is not the only factor in sign language lexical acquisition, or as Caselli and Pyers (2017) put it "the road to language learning is not entirely iconic." Frequency influenced the ISL-CDI scores and this effect was stronger in older children ( $>24$ months) than in younger children ( $<24$ months). Previous findings on spoken languages found no frequency effect for early lexical development (Goodman et al., 2008; Hansen, 2017). The explanation suggested by Goodman et al. (2008) is that most frequent items in parental input are closed-class (function) words (e.g., pronouns, prepositions, articles), yet these are learned later. Similarly, we found that the categories comprising closed-class words were underrepresented in early stages of ISL acquisition. Goodman et al. (2008) showed that the effect of frequency is modulated by children's chronological age and vocabulary size as it increases after the first 100 words. Our results are in line with this hypothesis. Our data show that the effect of frequency was more robust after the age of 24 months, when children's vocabulary size was larger than 100 signs.

Our findings are in line with the previous studies on spoken languages (Braginsky et al., 2016; Goodman et al., 2008; Hansen, 2017) and sign languages (Caselli \& Pyers, 2017), supporting the effect of frequency in vocabulary acquisition. Together the findings show that the effect of frequency changes over the course of early lexical development.

To conclude, the current study presented the development of the ISL-CDI parental questionnaire exploring its characteristics and supporting its validity as a tool for early vocabulary assessment in ISL. The findings support that children make use of both iconicity and frequency characteristics of the language to learn new signs and that these effects change over time.

Acknowledgment. This research was supported by the Israel Science Foundation (grant No. 1068/16) awarded to Rama Novogrodsky. The authors would like to commemorate the memory of our dearest and beloved colleague, Irit Meir, a key person in the current research who was involved in planning the ISL-CDI test, and passed in February 2018. The authors are grateful to the families and children who participated in the study and to the BIBI team: Adi Steg, Anne Marie Baer, Ora Ohanin, Roni Beit-Halachmi, and Tamar Haluzi who helped developing the ISL-CDI test and collect the data. We would like to acknowledge Hope Morgan, Hilla Gendler-Shalev, and Wendy Sandler for their comments on earlier versions of the paper, and the Institute for the Advancement of Deaf Persons in Israel for supporting us with the sign videos from the ISL dictionary.

\section{Notes}

1 The term language deprivation in the context of deaf children and children with hearing impairment is a label for different language dysfluency issues that tend to appear due to absent or inconsistent language exposure (Henner et al., 2018).

2 The category of body parts that are not signed with pointing was added to the questionnaire only after iconicity ratings were collected. Thus, this category is not explored in the iconicity effect on acquisition. 3 Following the policy of the MacArthur-Bates Communicative Development Inventories (CDIs), the newly developed ISL-CDI tool is available from the research team. See contact details of the authors.

4 In addition, following an anonymous reviewer's suggestion, we also collected iconicity ratings from 11 (7 females and 4 males) ISL native signers $\left(M_{\text {age }}=32, S D=10\right.$, Min-Max: $\left.20-53\right)$, who were exposed to ISL from birth and grew up in a signing home with one or two signing parents. They were from different areas of Israel (north, center, and south), representing different signing communities, and belonging to a 
mid-high socioeconomic group, as measured by years of education $(M=14, S D=2$ Min-Max: 12-16). Following the ASL acquisition study of Caselli and Pyers (2017), who used iconicity ratings from hearing adults (Caselli et al., 2017), in the current study, we also used the data from sign-naïve adults (see Results, Study $1 \mathrm{~A}$ ). However, it should be noted there were strong correlations in the iconicity rating scores between the ISL native signers and the sign-naïve adults $(r=.71, p<.001)$.

5 The gap between total number of signs $(n=563)$ and the number of signs reporting for iconicity $(\mathrm{n}=554)$ rating represents the fact that iconicity ratings were collected before signs of body parts that are not signed with pointing (e.g., FACE signing a circle around the face) were added.

6 These include the following signs: JEEP, PORRIDGE, RAISINS, ROCK, PICNIC, GAS STATION, THIN, AFTER, WAS (past), THESE, OUR, BETWEEN, NEXT TO.

\section{References}

Ali, A. \& Farage, D. (2017). The development of the ability to recognize iconic signs in Israeli Sign language: A comparison between children and adults. Unpublished seminar research.

Anderson, D., \& Reilly, J. (2002). The MacArthur communicative development inventory: Normative data for American Sign Language. Journal of Deaf Studies and Deaf Education, 7, 83-106.

Armon-Lotem, S., \& Ohana, O. (2017). A CDI study of bilingual English-Hebrew children-frequency of exposure as a major source of variation. International Journal of Bilingual Education and Bilingualism, 20, 201-217.

Armon-Lotem, S., de Jong, J., \& Meir, N. (Eds.). (2015). Methods for assessing multilingual children: Disentangling bilingualism from Specific Language Impairment. Multilingual Matters.

Arriaga, R. I., Fenson, L., Cronan, T., \& Pethick, S. J. (1998). Scores on the MacArthur Communicative Development Inventory of children from low and middle-income families. Applied Psycholinguistics, 19, 209-223.

Bavin, E. L., Bretherton, L., Rescorla, L. A., \& Dale, P. S. (2013). The early language in Victoria study: Late talkers, predictors and outcomes. Late talkers: Language Development, Interventions, and Outcomes, $3-22$.

Ben-Itzhak, D., Greenstein, T., \& Kishon-Rabin, L. (2014). Parent report of the development of auditory skills in infants and toddlers who use hearing aids. Ear and Hearing, 35, e262-e271.

Bornstein, M. H., Cote, L. R., Maital, S., Painter, K., Par, S.-Y., Pascual L., Pêcheux, M.-G., Ruel, J., Venuti, P. \& Vyt, A. (2004). Cross-linguistic analysis of vocabulary in young children: Spanish, Dutch, French, Hebrew, Italian, Korean, and American English. Child Development, 75, 1115-1139.

Braginsky, M., Yurovsky, D., Marchman, V. A., \& Frank, M. (2016). From uh-oh to tomorrow: Predicting age of acquisition for early words across languages. In CogSci.

Capirci, O., Iverson, J. M., Montanari, S., \& Volterra, V. (2002). Gestural, signed and spoken modalities in early language development: The role of linguistic input. Bilingualism: Language and Cognition, 5, 25-37.

Caselli, N. K. (2016). Parents Questionnaire. Boston University School of Education.

Caselli, N. K., \& Pyers, J. E. (2017). The road to language learning is not entirely iconic: Iconicity, neighborhood density, and frequency facilitate acquisition of sign language. Psychological Science, 28, 979-987.

Caselli, N. K., Sehyr, Z. S., Cohen-Goldberg, A. M., \& Emmorey, K. (2017). ASL-LEX: A lexical database of American Sign Language. Behavior Research Methods, 49, 784-801.

Chen-Pichler, D. (2012). Language Acquisition. In R. Pfau, B. Woll, \& M. Steinbach (Eds.), Handbook of linguistics and communication science: Sign language (pp. 647-686). de Gruyter.

Dachkovsky, S., \& Sandler, W. (2009). Visual intonation in the prosody of a sign language. Language and Speech, 52, 287-314.

Dale, P. S., Fenson, L. \& Thal, D. J. (1993). Development inventories to additional languages. Unpublished manuscript.

Degani, T. Krizer, V., \& Novogrodsky, R. (2019). The joint effects of bilingualism, DLD and itemfrequency on children's lexical retrieval performance. International Journal of Language and Communication Disorders, 54, 485-498.

de Saussure, F. (1916). Course in general linguistics. McGraw Hill.

Diessel, H. (2007). Frequency effects in language acquisition, language use, and diachronic change. New Ideas in Psychology, 25, 108-127. 
Dingemanse, M., Blasi, D. E., Lupyan, G., Christiansen, M. H., \& Monaghan, P. (2015). Arbitrariness, iconicity, and systematicity in language. Trends in Cognitive Sciences, 19, 603-615.

Edwards, J., Beckman, M. E., \& Munson, B. (2015). Frequency effects in phonological acquisition. Journal of Child Language, 42, 306.

ELAN (2018, April 4). (Version 5.2) [Computer software]. Max Planck Institute for Psycholinguistics. https://tla.mpi.nl/tools/tla-tools/elan/

Fenson, L., Bates, E., Dale, P., Goodman, J., Reznick, J.S., \& Thal, D. (2000a). Measuring variability in early child language: Don't shoot the messenger. Child Development, 71, 323-328.

Fenson, L., Pethick, S., Renda, C., Cox, J. L., Dale, P. S., \& Reznick, J. S. (2000b). Short-form versions of the MacArthur communicative development inventories. Applied Psycholinguistics, 21, 95-116.

Fenson, L., Dale, P. S., Reznick, J. S., Bates, E., Thal, D. J., Pethick, S. J., . . \& Stiles, J. (1994). Variability in early communicative development. Monographs of the Society for Research in Child Development, i-185.

Frank, M. C., Braginsky, M., Yurovsky, D., \& Marchman, V. A. (2017). Wordbank: An open repository for developmental vocabulary data. Journal of Child Language, 44, 677-694.

Frank, M. C., Braginsky, M., Marchman, V. A., \& Yurovsky, D. (2019). Variability and consistency in early language learning. The Wordbank Project.

Fuks, O. (2018). Two styles of infant-directed signing in Israeli Sign Language (ISL). A talk presented at the Sign Language Acquisition and Assessment conference (SLAAC). University of Haifa, Israel.

Gatt, D., O’Toole, C., \& Haman, E. (2015). Using parental report to assess early lexical production in children exposed to more than one. Assessing Multilingual Children: Disentangling Bilingualism from Language Impairment, 13, 151.

Gendler-Shalev, H., \& Dromi, E. (2020). The Hebrew Web MB-CDI-WG Norms: Lexical Development of Hebrew-speaking Toddlers. https://doi.org/10.17605/OSF.IO/VU2NA

Gilbey, P., Kraus, C., Ghanayim, R., Sharabi-Nov, A., \& Bretler, S. (2013). Universal newborn hearing screening in Zefat, Israel: The first two years. International Journal of Pediatric Otorhinolaryngology, 77, 97-100.

Gollan, T. H., Montoya, R. I., Cera, C., \& Sandoval, T. C. (2008). More use almost always means a smaller frequency effect: Aging, bilingualism, and the weaker links hypothesis. Journal of Memory and Language, 58, 787-814.

Goodman, J. C., Dale, P. S., \& Li, P. (2008). Does frequency count? Parental input and the acquisition of vocabulary. Journal of Child Language, 35, 515.

Goralnik, E. (1995). Goralnik screening test for Hebrew. Even Yehuda: Matan.

Hansen, P. (2017). What makes a word easy to acquire? The effects of word class, frequency, imageability and phonological neighbourhood density on lexical development. First Language, 37, 205-225.

Haug, T. (2011). Approaching sign language test construction: Adaptation of the German Sign Language receptive skills test. Journal of Deaf Studies and Deaf Education, 16, 343-361.

Henner, J., Novogrodsky, R., Reis, J., \& Hoffmeister, R. (2018). Recent issues in the use of signed language assessments for diagnosis of language related disabilities in signing deaf and hard of hearing children. Journal of Deaf Studies and Deaf Education, 23, 307-316.

Hoff, E., Core, C., Place, S., Rumiche, R., Señor, M., \& Parra, M. (2012). Dual language exposure and early bilingual development. Journal of Child Language, 39, 1-27.

Junker, D. A., \& Stockman, I. J. (2002). Expressive vocabulary of German-English bilingual toddlers. American Journal of Speech-Language Pathology, 11, 381-394.

Kohnert, K. (2010). Bilingual children with primary language impairment: Issues, evidence and implications for clinical actions. Journal of Communication Disorders, 43, 456-473.

Laing, C. E., Vihman, M., \& Keren-Portnoy, T. (2017). How salient are onomatopoeia in the early input? A prosodic analysis of infant-directed speech. Journal of Child Language, 44, 1117-1139.

Lederberg, A. R., \& Spencer, P. E. (2001). Vocabulary development of deaf and hard of hearing children. In M. D. Clark, M. Marschark, \& M. Karchmer (Eds.), Context, cognition and deafness (pp. 88-112). Gallaudet University Press.

Lee, J. (2011). Size matters: Early vocabulary as a predictor of language and literacy competence. Applied Psycholinguistics, 32, 69-92.

Mancilla-Martinez, J., Pan, B. A., \& Vagh, S. B. (2011). Assessing the productive vocabulary of Spanish-English bilingual toddlers from low-income families. Applied Psycholinguistics, 32, 333-357. 
Maital, S. L., Dromi, E., Sagi, A., \& Bornstein, M. H. (2000). The Hebrew communicative development inventory: Language specific properties and cross-linguistic generalizations. Journal of Child Language, 27, 43-67.

Massaro, D. W., \& Perlman, M. (2017). Quantifying iconicity's contribution during language acquisition: Implications for vocabulary learning. Frontiers in Communication, $2,4$.

Maurer, D., Pathman, T., \& Mondloch, C. J. (2006). The shape of boubas: Sound-shape correspondences in toddlers and adults. Developmental Science, 9, 316-322.

Meier, R., Mauk, C. E., Cheek, A., and Moreland, C. J. (2008). The form of children's early signs: Iconic or motoric determinants? Language Learning and Development, 4, 63-98. doi:10.1080/15475440701377618

Meir, I. (2002). A cross-modality perspective on verb agreement. Natural Language \& Linguistic Theory, 20, 413-450.

Meir, I. (2003). Modality and Grammaticalization: The emergence of a case marked pronoun in ISL. Journal of Linguistics, 39, 109-140.

Meir, I. (2006). Question and negation in Israeli Sign Language. Sign Language and Linguistics, 7, 97-124.

Meir, I., \& Tkachman, O. (2018). Iconicity. In Oxford Research Encyclopedia of Linguistics.

Mitchell, S., Brian, J., Zwaigenbaum, L., Roberts, W., Szatmari, P., Smith, I., \& Bryson, S. (2006). Early language and communication development of infants later diagnosed with autism spectrum disorder. Journal of Developmental \& Behavioral Pediatrics, 27, S69-S78.

Nicholas, J. G., \& Geers, A. E. (2006). Effects of early auditory experience on the spoken language of deaf children at 3 years of age. Ear and Hearing, 27, 286.

Novogrodsky, R., Meir, N., \& Michael, R. (2018). Morpho-syntactic abilities of toddlers with hearingimpairment and normal hearing: Evidence from a sentence repetition task. International Journal of Language and Communication Disorders, 53, 811-824.

Occhino, C., Anible, B., Wilkinson, E., \& Morford, J. P. (2017). Iconicity is in the eye of the beholder. Gesture, 16, 100-126. doi:10.1075/gest.16.1.04occ

Orlansky, M. D., \& Bonvillian, J. D. (1984). The role of iconicity in early sign language acquisition. Journal of Speech and Hearing Disorders, 49, 287-292.

Ormel, E., Hermans, D., Knoors, H. \& Verhoeven, L. (2009). The role of sign phonology and iconicity during sign processing: The case of deaf children. Journal of Deaf Studies and Deaf Education, 14, 436-448.

Ortega, G. (2017). Iconicity and sign lexical acquisition: A review. Frontiers in Psychology, 8, 1280.

O'Toole, C., Gatt, D., Hickey, T. M., Miękisz, A., Haman, E., Armon-Lotem, S., . . \& Kern, S. (2017). Parent report of early lexical production in bilingual children: A cross-linguistic CDI comparison. International Journal of Bilingual Education and Bilingualism, 20, 124-145.

Özçalişkan, Ş., Gentner, D., \& Goldin-Meadow, S. (2014). Do iconic gestures pave the way for children's early verbs? Applied Psycholinguistics, 35, 1143-1162.

Perlman, M., Little, H., Thompson, B., \& Thompson, R. L. (2018). Iconicity in signed and spoken vocabulary: A comparison between American Sign Language, British Sign Language, English, and Spanish. Frontiers in Psychology, 9, 1433.

Perniss, P., Thompson, R., \& Vigliocco, G. (2010). Iconicity as a general property of language: Evidence from spoken and signed languages. Frontiers in Psychology, 1, 227.

Perry, L. K., Perlman, M., Winter, B., Massaro, D. W., \& Lupyan, G. (2018). Iconicity in the speech of children and adults. Developmental Science, 21, e12572.

Rinaldi, P., Caselli, M. C., Di Renzo, A., Gulli, T., \& Volterra, V. (2014). Sign vocabulary in deaf toddlers exposed to sign language since birth. Journal of Deaf Studies and Deaf Education, 19, 303-318.

Rodríguez-Ortiz, I. R., Pérez, M., Valmaseda, M., Cantillo, C., Díez, M. A., Montero, I., . . \& Saldaña, D. (2020). A Spanish Sign Language (LSE) adaptation of the Communicative Development Inventories. Journal of Deaf Studies and Deaf Education, 25, 105-114.

Rowe, M. L., Raudenbush, S. W., \& Goldin-Meadow, S. (2012). The pace of vocabulary growth helps predict later vocabulary skill. Child Development, 83, 508-525.

Sandler, W. (2018). The body as evidence for the nature of language. Frontiers in Psychology, 9, 1782.

Sümer, B., Grabitz, C., \& Küntay, A. (2017). Early produced signs are iconic: Evidence from Turkish Sign Language. In the 39th Annual Conference of the Cognitive Science Society (CogSci 2017) (pp. 3273-3278). Cognitive Science Society. 
Tasci, S. S., Sumer, B., \& Eker, S. (2017). Comparison of iconicity judgments by deaf signers and hearing non-signers. A talk presented at the sixth meeting of the "Formal and Experimental Advances in Sign Language Theory" (FEAST), the University of Iceland, Reykjavik.

Taub, S. (2001). Language from the body: Iconicity and metaphor in American Sign Language. Cambridge University Press.

Thompson, R. L., Vinson, D. P., Woll, B., \& Vigliocco, G. (2013). The road to language learning is iconic: Evidence from British Sign Language. Psychological Science, 23, 1443-1448.

Tkachman, O., \& Sandler, W. (2013). The noun-verb distinction in two young sign languages. Special issue, Where Do Nouns Come From? J. Haviland (Ed.), Gesture, 13, 253-286.

Tomblin, J. B., Barker, B. A., Spencer, L. J., Zhang, X., \& Gantz, B. J. (2005). The effect of age at cochlear implant initial stimulation on expressive language growth in infants and toddlers. Journal of Speech, Language, and Hearing Research, 48, 853-867.

Vinson, D. P., Cormier, K., Denmark, T., Schembri, A., \& Vigliocco, G. (2008). The British Sign Language (BSL) norms for age of acquisition, familiarity, and iconicity. Behavior Research Methods, 40, 1079-1087.

Winter, B., Perlman, M., Perry, L. K., \& Lupyan, G. (2017). Which words are most iconic? Interaction Studies, 18, 443-464.

Woll, B. (2013) Sign language and spoken language development in young children: Measuring vocabulary by means of the CDI. In L. Meurant, A. Sinte, M. Van Herreweghe, \& M. Vermeerbergen (Eds.), Sign language research, uses and practices (pp. 15-34). de Gruyter \& Ishara Press.

Woolfe, T., Herman, R., Roy, P., \& Woll, B. (2010). Early vocabulary development in deaf native signers: A British Sign Language adaptation of the communicative development inventories. Journal of Child Psychology and Psychiatry, 51, 322-331.

\section{APPENDIX 1}

Fixed coefficients for the fixed effects of the binominal mixed-effects logistic regression

\begin{tabular}{|c|c|c|c|c|c|c|}
\hline \multirow[b]{2}{*}{ Model Term } & \multirow[b]{2}{*}{ Coefficient } & \multirow[b]{2}{*}{ Std. Error } & \multirow[b]{2}{*}{$\mathrm{t}$} & \multirow[b]{2}{*}{ Sig. } & \multicolumn{2}{|c|}{$\begin{array}{l}\text { 95\% Confidence } \\
\text { Interval }\end{array}$} \\
\hline & & & & & Lower & Upper \\
\hline Intercept & 4.303 & .5721 & 7.522 & .000 & 3.182 & 5.425 \\
\hline Age & -.148 & .0127 & -11.583 & .000 & -.173 & -.123 \\
\hline ICONICITY_L = 1 & .450 & .3730 & 1.206 & .228 & -.281 & 1.181 \\
\hline ICONICITY_L $=2$ & .734 & .2620 & 2.803 & .005 & .221 & 1.248 \\
\hline ICONICITY_L = 3 & .816 & .2563 & 3.182 & .001 & .313 & 1.318 \\
\hline ICONICITY_L $=4$ & .601 & .2588 & 2.322 & .020 & .094 & 1.108 \\
\hline ICONICITY_L $=5$ & .341 & .2530 & 1.348 & .178 & -.155 & .837 \\
\hline ICONICITY_L $=6$ & .555 & .2589 & 2.145 & .032 & .048 & 1.063 \\
\hline ICONICITY_L = 7 & $0^{b}$ & . & . & . & . & . \\
\hline FREQ_L $=2$ & 4.805 & 3.0060 & 1.599 & .110 & -1.087 & 10.697 \\
\hline FREQ_L = 3 & .312 & .3693 & .844 & .398 & -.412 & 1.036 \\
\hline FREQ_L $=4$ & .495 & .2267 & 2.185 & .029 & .051 & .940 \\
\hline FREQ_L $=5$ & .481 & .1744 & 2.759 & .006 & .139 & .823 \\
\hline
\end{tabular}




\begin{tabular}{|c|c|c|c|c|c|c|}
\hline FREQ_L $=6$ & .376 & .1386 & 2.715 & .007 & .105 & .648 \\
\hline FREQ_L $=7$ & $0^{\mathrm{b}}$ & . & . & . & . & . \\
\hline Age $^{\star}[$ ICONICITY_L $=1]$ & .010 & .0102 & .989 & .322 & -.010 & .030 \\
\hline Age $^{\star}[$ ICONICITY_L $=2]$ & .010 & .0078 & 1.333 & .183 & -.005 & .026 \\
\hline Age $^{\star}[$ ICONICITY_L $=3]$ & .001 & .0077 & .099 & .921 & -.014 & .016 \\
\hline Age $^{*}[$ ICONICITY_L $=4]$ & .006 & .0078 & .712 & .476 & -.010 & .021 \\
\hline Age $^{\star}[$ ICONICITY_L $=5]$ & .009 & .0077 & 1.196 & .232 & -.006 & .024 \\
\hline Age $^{*}[$ ICONICITY_L $=6]$ & -.005 & .0080 & -.572 & .568 & -.020 & .011 \\
\hline Age $^{*}[$ ICONICITY_L $=7]$ & $0^{b}$ & . & . & . & . & . \\
\hline $\mathrm{Age}^{\star}[\mathrm{FREQ} \mathrm{L}=2]$ & .004 & .0425 & .101 & .920 & -.079 & .088 \\
\hline Age*$^{*}[$ FREQ_L $=3]$ & .046 & .0076 & 6.013 & .000 & .031 & .060 \\
\hline 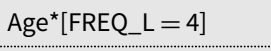 & .037 & .0054 & 6.849 & .000 & .026 & .047 \\
\hline $\mathrm{Age}^{\star}[\mathrm{FREQ} \mathrm{L}=5]$ & .027 & .0047 & 5.778 & .000 & .018 & .036 \\
\hline Age $^{\star}[$ FREQ_L $=6]$ & .013 & .0042 & 3.051 & .002 & .005 & .021 \\
\hline Age*[FREQ_L $=7]$ & $0^{\mathrm{b}}$ & . & . & . & . & . \\
\hline
\end{tabular}

${ }^{\mathrm{b}}$ This coefficient is set to zero because it is redundant.

Cite this article: Novogrodsky, R. and Meir, N. (2020). Age, frequency, and iconicity in early sign language acquisition: Evidence from the Israeli Sign Language MacArthur-Bates Communicative Developmental Inventory. Applied Psycholinguistics 41, 817-845. https://doi.org/10.1017/S0142716420000247 